\title{
Ethics, economics, and markets: an interview with Debra Satz
}

DEBRA SATZ is the Marta Sutton Weeks professor of ethics in society and professor of philosophy and (by courtesy) political science at Stanford University. She also directs Stanford's Bowen H. McCoy Family Center for Ethics in Society. Prior to coming to Stanford in 1988, Satz taught at Swarthmore College. She has also held fellowships at the Princeton University Center for Human Values and the Stanford Humanities Center and was the Marshall Weinberg distinguished visiting professor at the University of Michigan in 2002. Satz grew up in the Bronx and received her B.A. from the City College of New York and her PhD from MIT in 1987.

Professor Satz's research interests range widely including social and political philosophy, philosophy of social sciences, philosophy of economics, and feminist philosophy. Her work has appeared in Philosophy \& Public Affairs, Ethics, Journal of Philosophy, and World Bank Economic Review. Her main research interest for the last decade concerns the limits of the market: Are there some things that should not be for sale? Kidneys? Sex? International weapons? Should the reach of markets be limited for reasons other than efficiency and distributive justice? Her new book addressing these issues is entitled Why some things should not be for sale: the moral limits of markets and will be published by Oxford University Press in June 2010.

EJPE interviewed professor Satz in early October 2009 when she visited Erasmus University Rotterdam to present material from her new book at the Research Seminar of the Erasmus Institute for Philosophy and Economics.

EJPE: Professor Satz, perhaps you could start by saying something about the trajectory of your career as a philosopher and the events, people, or writings that have had a particular influence on the development of your interests.

EJPE'S NoTE: This interview was conducted by Thomas Wells and Rutger Claassen. Wells is a doctoral student at the Erasmus Institute for Philosophy and Economics (EIPE), Erasmus University Rotterdam, and a co-editor of the Erasmus Journal for Philosophy and Economics (EJPE). Claassen recently completed a $\mathrm{PhD}$ thesis on The market's place in the provision of goods, and is now an assistant professor in political philosophy at Leiden University, The Netherlands. 
DEBRA SATZ: I was from a poor family but did well in school, especially in math. My love of math took me to MIT to study logic as a graduate student with George Boolos. During the time I was at MIT a number of things were going on in the world around me. The United States was playing a largely negative role in the wars in Central America. I had always been political and I had always worried about the state of the world-some of that comes from being from a working class familyand I realized that I was spending more time thinking about politics (and acting) and less time on logic.

At that point, I happened to sit in on a course by John Rawls and enrolled in another by Joshua Cohen at MIT. I began to think that maybe there was a way to bring my intellectual interests closer to my political interests-Rawls and Cohen showed me that philosophy could have practical aims. Not only can philosophy help a person to reason clearly and cogently about an issue, but it can also help her explore the bounds of the possible; teach mutual respect as the basis of argument; and help her discover what she really cares most deeply about. But to do some of these tasks-to explore the bounds of the possible, for examplepolitical philosophy has to be in conversation with empirical social science. I found this mutual interaction between social science and philosophy very exciting, and it also opened up the possibility that some of my mathematical training could be of use. When Gerry Cohen wrote Karl Marx's theory of history: a defence (1978), I saw the possibility of exploring further the nature of social science explanation as a philosopher and I wound up writing a dissertation that examined the role of moral values in Marx's empirically based theory of history.

What do you consider to be the role of a philosopher, and perhaps specifically of a philosopher of economics? For example, should it be limited to academic analysis or take a broader form, and if so what?

I believe that philosophical work and reflection arises from problems that emerge in everyday thinking that everyday thinking cannot resolve. For example, when the dominant form of everyday thinking was religious, philosophers of the medieval period naturally wrote a great deal on religion, and since science has become dominant it is no surprise that so much of philosophy has turned to reflections on science. I have the same view of political philosophy and philosophy of economics: it speaks to questions that arise in our everyday thoughts about the world. For example, a political philosopher who today wrote a 
defense of slavery, no matter how analytically consistent and coherent it was, would be speaking to no one; at least I hope that is so. Debates about slavery are settled parts of our culture.

This does not entail shutting off more utopian ways of thinking, but even utopian ways of thinking have to connect in some way to the world of the possible. And they have to connect with history and aspirations.

So does that also mean that philosophers should bring their philosophical answers to the audience-should they write in newspapers and appear on television and radio shows, or confine themselves to publishing their answers in journals that, to put it kindly, nobody reads or perhaps even has access to?

To some extent a division of labor makes sense because people who are good at one thing are not good at another thing: some people are good at raising issues and drawing our attention to new distinctions but not good at writing for a general audience. At the same time, I think philosophy-especially political philosophy-removes itself from the world at its own peril. Not only is it harder to justify practically, but also since I think political philosophy is nurtured by real living debates and aspirations, I think it gets stale if it is done in isolation from public concerns. And I do think that philosophers-and all academics-have an obligation to share their important findings with a wider public.

There is a quote of Gramsci's that I have always liked which goes something like this: "An original idea that remains the property of a few people is a less important intellectual event than the dispersal of an old idea among masses of people who never knew it before". We should not devalue the activity of trying to involve lots of different people in philosophical conversation. Gramsci's point was that that was a philosophical contribution too. In fact, I think the most important thing I do is to teach, because that is probably the most direct way I can reach lots of people, people who will go on and do many different things in society. If you write for a journal that only ten people read, it does not mean that what you are doing is not important, but if what you write is important and it only stays with those ten people that is a problem. Somebody else ought to be trying to spread that idea, and there are people who popularize the ideas of other people, which I think is an invaluable thing and hard to do well. Neither of my parents went to college and so I have my own test for my writing-I have probably failed 
it-but I try to write in a way that does not set the bar so high that unless you have a $\mathrm{PhD}$ in philosophy you cannot read what I write.

\section{Do you feel any particular identity as a philosopher of economics, and does anything follow from that?}

Often when people talk about philosophy of economics they are really thinking about it as a branch of philosophy of science. The questions that understanding raises are not ones that I am expert in or where my main interests are located. I think a lot about markets, which are some of the most important economic institutions of our time. So, naturally I have to engage with economic reasoning about markets and reflect on the limits of that reasoning. I am interested in the places where moral and political questions about markets arise that economics itself is not designed to answer. I am interested in whether economic theory has all the tools it needs to assess markets as institutions. This leads me to think about the minimal presuppositions in economic theory about human psychology, about the relationship between markets and moral motivations, and about the nature of concepts such as that of an externality. So I would say I am a political philosopher with strong interests in economic theory and in how economic institutions play a role in political and social life.

\section{But aren't theoretical economics and political economy quite different areas of study? How do you bring them together?}

Of course, but they were not always distinct. And many theoretical models have presuppositions that turn out to be problematic when you put them into practice or consider their larger context. Consider the question of what counts as part of the economy. If you look at how the ILO (International Labour Organization) and a lot of economists have approached child labor, at who they counted as a child laborer, it turns out that in some countries $40 \%$ of the children were missing. This is because when you add up the kids employed in the formal market sector and the kids in school you only get about $60 \%$ of the kids that population statistics predict. Admittedly, data collection is bad in many poor countries but still that is an enormous percentage of missing children. It turns out that they were missing because no-one had counted children being employed in the home or kept at home to care for siblings so that their mothers could work. Most of these missing children were girls. So here is a point where an assumption of economic 
theory can blind us to something that is practically important, that has all kinds of ethical ramifications, that has policy ramifications.

How far do you think academic economics is significant for the real world? You have used the example of Lawrence Summers's infamous memo on the welfare efficiency of shipping toxic waste to poor countries $^{1}$ as an example of economic logic with problematic implications, but of course such proposals were never taken seriously.

Well there was the Washington Consensus where the IMF really took over the Chicago School's economic theory lock, stock, and barrel and then applied it to developing countries. For a long time, economists proceeded as if there was a fixed recipe for economic development and it was the same for every country. Then they saw that the recipe did not produce development in many cases-or if it produced development it produced it unevenly and with a lot of social suffering-and in places like China where the recipe was not followed there was enormous development. So, now the discipline is more open to considerations about institutions, governance, free press and women's rights. But harm was done by the previous attempt to impose the recipe. So I think that bad theory can have very bad consequences.

Even apart from the particularly direct influence on the IMF, mainstream economics has had a big although sometimes indirect influence. Many students take away two points from introductory economics courses: that regulations are inefficient and that markets are efficient. But these points are generalizations and over-simplistic. And that again is why teaching matters.

Of course, many bad social outcomes are not caused by bad ideas. In my paper with John Ferejohn, "Rational choice and social theory" (1994), we looked at the role of institutions in producing outcomes. Sometimes institutional constraints matter more for explanation than individual ideas or motivations.

In that paper on rational choice theory with John Ferejohn you argued against the naive view that rational choice theory was a psychological theory, and suggested that it was useful only in cases of agents with clear goals and severe external constraints. That work attracted lots of attention from economic methodologists.

\footnotetext{
1 Summers was chief economist of the World Bank when he sent the memo in December 1991.
} 
Nevertheless since then you seem to have turned away from the analysis of economic method and back towards a wider-ranging critique of contemporary political economy (particularly with regard to the moral limits of markets). Is that a fair assessment? Does this reflect changes in your understanding of philosophy of economics? How do you see the paper now?

Dan Hausman wrote a response to that paper soon after we published it, also in the Journal of Philosophy (Hausman 1995). We have been wrestling with a response to that and other criticisms for many years. We have published one follow up paper (Satz and Ferejohn 1995), and we have others in draft form that neither of us is happy with. So, it is still an ongoing interest of mine but it has been on the back-burner. I would still defend the basic idea of that paper: the abstraction of "rational economic man" can be helpful in some contexts, but not in others. Consistency and transitivity are not always necessary. Similarly, markets work well in some contexts but not well in others. They tend to work well when we are dealing with arms lengths transactions between strangers, with many participants, none of whom has power over the others. They tend to work best in environments where choices are constrained. We have to be careful about our generalizations.

There has been an ongoing debate about 'economics imperialism' in academia at least since Gary Becker's 'economic approach'. Would you characterize the ongoing expansion of economic analysis beyond traditional economic subjects and concepts as imperialist or as something else? Does it have important consequences and if so should it be resisted?

I think "imperialism" has to be evaluated on a case-by-case basis. Unification of domains that have been previously viewed as distinct is sometimes positive: it can help you understand things better that you did not understand before. Sometimes the application of economic methods to political science has yielded insights that some phenomena that people thought were random have an underlying structure that allows us to make some predictions and understand them better. But it is more problematic when what you are unifying has distinct characteristics that you now overlook.

Richard Posner's book Sex and reason (1992), is an example of problematic unification. There, he analyses sex in terms of an economic model. While that has some plausibility when we are dealing with male- 
female sex ratios and certain social practices, it can be taken to absurd levels. For example, he conjectures that women wear high heels to signal to men that they will be faithful and not run out on them with other men. The danger is that all social practices will be viewed as having a rational explanation. In his book, economic reasoning and Darwinian evolution are used to explain an enormous variety of human practices, but many of these practices may owe their origins to contingencies, or to power, or to other causes.

Whether or not using an economic approach yields insights varies case-by-case. I am all for intellectual imperialism if it generates some useful knowledge. I do not have an a priori view that it is only in one domain that economic methods will generate insights. But I suspect that economic analysis is going to be better at generating insights in domains analogous to the one it was designed for: arms-length transactions between large numbers of strangers.

Some philosophers, for example Ingrid Robeyns, argue that philosophers should get more involved in economics, because economists are making philosophical mistakes. But what do you think really drives the course of academic economics? For example, the internal institutional values and publishing 'incentive structures' of economics departments, real world problems or events, or the intellectual issues with which philosophers are concerned? Is economics different from other social sciences in this regard?

I share Ingrid's concern that economics is much less pluralistic than other social science disciplines. I have a courtesy appointment in political science and if you look there, or at sociology, anthropology, or psychology, there are different methods for approaching the phenomena that are being studied. Although some methods have more prominence in each field than others, there is a pluralistic space. And I think economics does not have as much pluralistic space. Work in experimental economics, and even in behavioral economics, has not been well represented in the elite economics departments. Few, if any, courses look at the assumptions behind the discipline and there is little attention to the history of the discipline.

Of course, this is just a sociological description. It could be that all these other disciplines are methodologically pluralist because they are not yet scientific disciplines, but economics is. But I don't think that is the likely explanation because I just don't think we know enough about 
how the economy works-and I think recent events show that-to be confident about any models that we have. Economists would do better to be more open to questioning basic assumptions, and collaborating with other disciplines including philosophy, anthropology, political science, biology and the like. Economists studying poverty have a lot to learn from these other disciplines and vice versa. While economics has made some important advances, I think that we do not know enough to settle on one framework and therefore we should be more open

It is also unfortunate that economists have paid so little attention to ethics. Think, for example, about welfare economics. You can get a $\mathrm{PhD}$ in economics, with a focus in welfare economics, and yet have no idea about what welfare is, what the competing views of welfare are, and what values might not be captured by measuring it in standard ways. Or never think about the assumptions that go into defining GDP. Or take another example. Economists use the concept of externality to analyze why markets sometimes fail. But a little reflection will show that almost any transaction in a complex economy generates an externality: high rise apartments block the sunlight of their neighbors; cigarette smoke circulates; some people disapprove of the lifestyle purchases of others. If the concept of externality is to do any work, we have to separate harmless externalities from harmful ones. Nothing in economic theory gives us guidance about how to do this.

\section{Do you think that formalism is part of the problem?}

I think that formalism has driven out alternative approaches (approaches that may be harder to formalize), because it is so highly valued. I think that some policymaker once said something to the effect that "If we can't count it then it doesn't exist". So things that cannot be precisely quantified or modeled tend to be ignored, but that does not mean that they are not real or important or influencing what happens in the economy.

You have identified some philosophical problems with economics, but thinking about the future and how they might be fixed, do you think that can be done philosophically through the kind of approach you have been taking in your work, or do you think more institutionally focused reforms would be needed, for example with regard to the incentives in many economics departments to only publish in certain highly orthodox and formal journals? 
I think you do have to have some institutional changes because-at least in the US-if a graduate student in economics published in Economics and Philosophy or Philosophy and Public Affairs they would get zero credit for it. And students know that, so they know that it is not really worth their time to take courses in ethics or political philosophy, and so they don't, and that just reproduces a narrow discipline. So institutionally I would try to open that up, but it is very very hard to change that culture, or any culture.

On the other hand, work in development economics, mechanism design and behavioral economics do open up the possibilities of collaboration between economists and other disciplines that might lead to broader approaches.

There does seem to be a large restructuring of mainstream economics underway, but the new approaches coming to prominence seem to come more from other sciences, notably biology and psychology, than from the 'traditional' heterodox traditions such as institutionalist, Marxian, or feminist economics which would seem to have more in common with your concerns. Are you happy with this new direction economics is taking?

Well it depends on what you think of experimental economics, for example, as showing. Take the kind of studies by Ernst Fehr and others on cooperation. I think that work is very exciting. They show that when we look at how people behave in dictator and ultimatum games in different societies they do not behave the way economic models would predict. They are not rational maximizers; they are guided by norms, including norms about what is right or just. Abstracting away from norms does not give us good models or predictive theories. That is not just bringing physics in-this work opens up the question of what the relationship is between economic reasoning and norms. Indeed, there is work by experimentalists suggesting that studying economics undermines certain norms-for example, that it makes students less altruistic-and that is pretty important if it is true. There again we have to think about the interplay between economic systems, methods and norms. So I think that some of the experimental work opens up in a direction that is not unfriendly to what some feminists and radical economists were saying earlier on. 
In your previous work on markets in women's reproductive labor (Satz 1992) and sexual labor (Satz 1995), you argued that we should reject the economic approach to the moral limits of the market, which holds that in principle all goods should be for sale. Can you explain what is wrong with the economic approach with respect to these markets?

I think I should have said "an" rather than "the" economic approach, leaving open the possibility that there is more than one way of using economics to illuminate the limits of markets. But what I meant by 'economic approach' is the idea that we can approach any good from the point of view of given this supply and this demand here is how this market will behave, here is the price at which it will clear, and so on, apparently without any normative assumptions. These papers argue that if we just think about sex markets like that, as if they were apple markets, then we are missing some important features of those markets.

Earlier political economy was very sensitive to the differences between labor markets and apple markets. If you go back to Adam Smith, Ricardo, Marx, they all thought of markets as heterogeneous and, in particular, they thought of some markets as having endogenous effects on the agents who were transacting in them. Smith worried that the people working in the pin factory would become pinheads because that is all they did all day, and that without intervention in that market the working population would sink to a level where they could not function as citizens. You do not have to worry in an apple market, in general, about the effects of the market on the apples, but you do have to worry in markets where human labor or sex are traded about the effects of those markets on people. Although it is not as if you could not build economic models that take into account these other features such as endogeneity, the formalism of contemporary economics tends to preclude that.

So how could contemporary economics incorporate that endogeneity and, if it did, wouldn't that deal with your objections and render the different approach you take in those articles redundant?

Even if economists took endogeneity into account that still would not fully deal with my objections, because you would still need political philosophy or ethics to tell you when the endogeneity effects matter: when they are troubling, and when they are not. That is not within the 
scope of the tools that economics has and so you have to look to other disciplines to answer that.

In these articles, your concern with contract pregnancy and prostitution is that these sales are made against a background of gender inequality. Defenders of the economic approach could respond that they can accommodate this concern, since market exchanges need to be voluntary for them to be genuine market exchanges. And voluntariness depends on the availability of alternative options. How would you respond?

There is a quote from Milton Friedman where he says that markets have (Paretian) optimality properties provided that the transactions are voluntary and informed. But economists pay too little attention to what it means for a market to be voluntary despite the fact that it is such a critical notion in economics. And what counts as voluntary is indeed a vexed issue. The fact that there is inequality underlying a transaction does not show that there is not voluntariness-at least on most views about voluntariness. At any rate you need a background theory to show when some choices are voluntary and when they are not. In a sense, even the choice to hand over your money to someone who says "your money or your life" is a voluntary one. To show that the choice of prostitution is involuntary you would have to show that there is something especially problematic about the set of alternatives women in prostitution face. That is unlikely to always be the case. In my articles, I concede the point that prostitution and commercial surrogacy can be voluntary but argue that there are other criteria for the legitimacy of choices other than the fact that they are voluntary.

My argument about prostitution does not deny that the choices are voluntary but it simply says that that is not enough to generate an argument that they are legitimate. I argue that in practices like prostitution there are likely to be ethically significant externalities that affect other people who do not choose to participate in the practice. The gender inequality that I hypothesize may arise in a prostitution market or a surrogacy market-operates via third party effects. It is what the market does to the way a group-women-are viewed that is objectionable although the group itself is not a participant in the market, only single individuals are.

That is still a hypothesis because it depends on empirical evidence. If you can show that widespread markets in women's reproductive labor 
and sexuality have effects on the way women are viewed and view themselves, then it is troubling. If you cannot show those third party effects, then I argue that prostitution is not necessarily troubling, although some instances of prostitution may be troubling because the women are controlled and beaten by their pimps, desperately poor, and so on.

In effect, I make a Parfit inspired point about third party effects: that an act that in a single case is acceptable might not be acceptable if it is held as a general rule. Think about child labor. Child labor for one family can be an improvement insofar as it provides the family with needed income, but if you allow child labor as a practice then you will drive down the price of adult labor and families that do not want to send their children to work will no longer be able to afford not to. Similarly, if you allowed prostitution as just another form of work-and it was linked with employment so that it became part of the job description for many jobs that you would have to have sex with the boss because it is just another kind of work-you would be imposing a cost on people who do not want to engage in that. They are going to have a different set of employment opportunities than they would have had had this market been closed off.

Now it is true that lots of markets have these third party effects. But at the least this point undermines the Pareto defense because it shows that a Pareto defense does not apply here.

That last point sounds similar to that of those philosophers, such as Elizabeth Anderson, who argue that having markets in certain goods will distort or corrupt the qualities of those things even for non market participants.

My argument here does not directly link to the qualities of the good, but to the choice sets of other people. This is another point about endogeneity: sometimes including an element in a choice set changes the options that are available for everyone, so that although it looks like you have added an element, you have actually taken away some other elements by making them unsustainable.

So again, for child labor this argument is not about changing the meaning of childhood, it is that you have added the element for the option to have child labor and what that has done is change the set of options for parents who do not want to have their children work, because now the adults make less money so it is much harder for them 
to effectively have the option not to send their kids to work. Whereas if you had closed off that option, it would have been easier for them not to send their children to work.

Nonetheless I do agree that a society with widespread child labor changes the meaning of childhood. There are probably third party endogenous effects with child labor in terms of how children are viewed by themselves and others. Some have argued that child labor itself reflects a certain view of children, or at least the children of the poor, as expendable and inferior.

But take a case for restricting a market that does not look at all like it depends on the meaning of the good-minimum wage laws. On the one hand, you could say that what minimum wage laws do is block some exchanges that people would want to make if they could. But arguably one of the things that will happen when you do not have minimum wage laws is that there are some options that people will not have in their set. For example, when there are minimum wage laws, employers have an important incentive to develop labor capacity and make labor more productive. This may lead them to invest in worker training programs, and care about the health of their employees. But when labor is cheap they may find themselves without this incentive. So even though minimum wage laws deprive people of an option, they also make possible other options. Workers as a group are arguably better off when employers have reason to invest in the development of their capacities.

In your article on markets for human kidneys (Satz 2008) you argue that prohibiting the sale of kidneys may be autonomy-enhancing for society as a whole. Could you explain?

The argument is essentially analogous to the argument I just made about minimum wages. You can think of it as an argument on behalf of a kind of collective paternalism-society closes off a choice to individuals to preserve other choices within the society. Closing off kidney markets may lead to more freedom for people overall, even though you have closed off this one kind of freedom.

This point bears on some early economists' objections to Titmuss's argument about blood markets. Titmuss argued in his book The gift relationship (1970) that if you have a market in blood, it will undermine altruism and you will have less gift-giving of blood and blood of an inferior quality since people will have an incentive to conceal any health problems they have. In his 1972 review, Ken Arrow accepted the point 
about the lower quality of blood through a market system but denied the point about quantity being diminished. Since, he wrote, all you are doing when you allow a market is giving people an additional option; this should not effect the decision of altruists. They can still donate their blood and others can sell it.

Titmuss did not have any mechanism for showing why his result would obtain. There is now a good deal more support for the fact that adding an option sometimes makes other options less available. Bruno Frey is probably the person who has done the most work on this (see e.g., Frey 1997). The classic example is the "natural experiment" of an Israeli day-care center that charged parents fines to discourage them from coming late, but found that lateness actually increased-the parents did not feel guilty anymore because they just paid the fines (Gneezy and Rustichini 2000). Payment "crowded out" their altruistic concern for the daycare workers.

In these articles, but especially in your article on 'noxious markets' (Satz 2004) and your new book, you propose a theory of democratic equality to assess the moral limits of the market. Can you explain the main tenets of this theory?

The starting point of my article-and my book-is that people respond quite differently to markets in certain goods than to other markets. Think about markets in "blood diamonds", international debt, child labor, kidneys, and prostitution. These markets elicit unease even among those who are otherwise enthusiastic about the market system. The question is whether there is anything we can say systematically about these reactions, or whether they simply reflect a primitive "repugnance". I think that there is something more that we can say. These markets all have some important departures from the markets of ideal theory. I analyze problematic markets in terms of four parameters, some of which are consistent with contemporary economic frameworks and some of which will take us outside economic frameworks.

Two of the parameters involve the sources of the market. The first is what I call 'weak agency', which happens in cases where people either lack important information about the nature of the market (as can happen when the consequences of the market extend into the distant future) and/or they are not participants in the market (as when dictators trade resources on the international markets that do not then benefit the populations of their countries). The second parameter concerns 
vulnerability - that some markets emerge when people are desperate or have very unequal needs for the goods at stake. When we see that kind of desperation and inequality, the market inherits it, and that is part of what makes us respond to the market as problematic. We do not think people should be so poor that they have to sell their kidneys to put food on the table.

The other two parameters concern the consequences of markets: some can be extremely harmful for individuals, others can be extremely harmful for social relations in a democratic society. So, for example, consider markets in toxic waste. Some of the effects of storing and transporting toxic waste are likely to be very bad for people-either people who are alive now or for future generations. Markets in blood diamonds are used to wage bloody civil wars where thousands die. In these cases, the harms brought about as a result of such markets rightly elicit our concern and even outrage. Other markets have deleterious social effects. Think about a market in votes. Although it is easy to show that a vote market might be efficient, a democratic society depends on the prohibition of such a market. (It also depends on prohibiting the free exchange of votes.) Or think about the ways that certain markets shape us-who we are, what we can do and hope for. In this category I would put labor markets, child care markets, and markets in education.

What ties these four criteria together? The parameters do not always go together-some markets are very bad because they have bad effects for individuals, but they do not arise from the weak agencies or underlying vulnerabilities of the transacting agents. But I believe that all noxious markets involve high scores along at least one of these parameters.

One way that these parameters go together is through their relationship to democracy. You cannot have a democracy, I argue, without important restrictions on noxious markets. And some markets, if not regulated can become noxious. If education were treated solely as a market good instead of also as a right, this would undermine democracy. In my 2004 paper and forthcoming book I develop what I call a 'democratic theory of citizenship', taken from T. H. Marshall: there are some basic requirements for being a citizen and markets which depress people below those requirements are worrying. That does not necessarily mean we should block such markets, but at the very least we have to supplement markets in these goods with non-market provision. 
Democratic citizenship is a demanding standard. And while I think it is appropriate to analyze markets using that standard, I want my theory of noxious markets to cover non-democratic contexts such as child labor in Pakistan where it is not about democratic relations, it is about extremely harmful consequences for children. But in a democracy, we have reasons to care even more about the scope of markets and their operation, and so I take the more minimal criteria specified by my four parameters and build it up into a more robust theory that says that democracies have special reasons to worry about the domain of the market.

The most hotly debated issues in the Netherlands with respect to the introduction of markets-as in many other countries-are (higher) education, health care, and social welfare services (e.g., job reintegration). What would your theory of democratic equality say about these types of cases, where what is at stake is not so much the sale of goods or services from the personal sphere, but the privatization or marketisation of services belonging to the public sector?

I think you can evaluate any of these markets along the parameters I have given. As I mentioned, these markets have endogenous effects: education markets and childcare markets really make people in certain ways. So you have got to pay attention to how you are making people, and what kind of people you are producing by these markets. These are not apple markets: we have reason to want our education system to produce more than docile and servile adults.

Let me elaborate on the education example. If we just treated education like any other kind of consumer preference you could, for example, educate children to be pets. But we have a lot of reasons not to allow this and therefore reasons to prevent consumer preferences from driving the content of education. There is also weak agency in education, because children's interests are at stake but they are not the consumers in the market-generally it is their parents making decisions. The state has an interest in making sure the interests of children are protected over the consumption interests of the parents.

At the same time, I do not think my arguments about limiting the market can specify the institutional answer to these issues because different institutional arrangements can be compatible with democratic citizenship. Think about markets in healthcare. One could imagine a 
system in which all healthcare is publicly provided by a single payer system, and one in which a market system is supplemented with publicly provided healthcare.

My theory is compatible with different modes of provision and I think you would have to look at the effects of those modes on the values that I stake out. But in the case of democracy, there are other values at stake besides extreme harm to individuals. There are values like equality of opportunity that are built into the idea of equal citizenship-no one as a result of their birth alone deserves more opportunity than anyone else. So you have to think about how the provision and distribution of education, whether through a market or a non-market or some combination, interacts with the political requirements of equal citizenship. There are lots of reasons to be worried about how education is provided. For example, one of the striking facts about education in the United States is that there are more children now being educated by home-schooling than through private schooling. This is an enormous movement and I would call it gift-giving because the parents are giving out their labor. It has all kinds of worrying effects from the point of view of a democratic, egalitarian society because parents are often home-schooling their children for religious reasons: because they do not want their children hearing about Darwin in the schools, they do not want them hearing about different ideas about sexuality, they do not want them learning about different religions. There are all kinds of worrying things about that sort of provision, even if the kids can pass some multiple-choice tests. All your examples-education, health care, social welfare services-involve cases where the endogeneity effects are very significant and have to be taken into account when we look at the provision of these goods, whether by markets or by other institutions.

While most people never engage in receiving or providing prostitution or the sale of kidneys, nearly everyone in developed countries is significantly exposed to public services such as the education and health care systems. So shouldn't your theory of the market be more ambitious in what it can say about those cases?

My theory does not say whether market provision is acceptable or not in the abstract, but it says that if there is a market, it will have to be limited in some way to safeguard or guarantee the values at stake. To what extent do you rely on the market, to what extent do you rely on the 
public sphere, to what extent do you rely on altruism in the provision of healthcare and education? I do not think my theory or any philosophical theory, can deliver determinate answers to that question. That seems to me a political question, not a political philosophy question. The political philosophy question is to try and point out the constraints on the domain of decision-making. What values ought to constrain our decisions? What values are important to promote in our institutional designs? But even once we have set those constraints, there are going to be a lot of close-to-the-ground empirical factors that have to be taken into account, and there is going to have to be some room for publics to reasonably disagree about different trade-offs. But you do want to see when you have reason to accept a constraint, that says here are the reasons not to trade off over here.

Many political philosophers set up an opposition between "the market" and "the state". One has the impression that you do not see that contrast; that you see markets merely as instruments for whatever we decide politically should be done, and in accordance with the political values we decide should be important. But don't you somehow assume that a country's politics will already meet some minimal requirements, for example of democratic institutions?

I think of markets as political institutions that depend on regulation and property rights. On my view, true laissez faire is not an option: all markets depend on background rules that are enforced. I am not even sure that we really have markets in some developing countries, because they often do not have the preconditions for a market society, such as enforceability of contracts. There are also de facto monopolies in many markets in poor countries, certainly in the credit market. Markets have certain political preconditions, but I would not go so far as to say that markets can only exist in democratic societies.

Nonetheless, I do not see market and state as rivals, the way they are often portrayed. Moreover, there are diverse markets (as I have been arguing) so "the market" is itself a heterogeneous domain. Finally, there are a lot of modes of provision between market and state. We need an expanded menu of modes of provision between those two: gift, philanthropy (which can involve a more collective gift-giving), selfprovision, lottery, compulsory service. There are a lot of different modes of provisioning that we have to consider. 
The last chapter of my book is actually about the policy implications of the approach that I defend. I argue that there is no way to deduce from the fact that a market is problematic to what we should do institutionally. In part that depends on which of the parameters are in play. If the problem is vulnerability, for example, you might leave the market in place but try to diminish vulnerability using a tax and transfer system. If the problem is weak agency, you might use mechanisms to increase information, like informed consent. What you do with a noxious market is going to vary case-by-case and also be the subject of a lot of political debate-quite correctly-because there may be a trade off of values.

So in the case of a weak country like Nigeria, you would say that it is not the untrammeled "market" causing the corruption, poor public services provision, and so on, since in fact there are no proper markets in the first place because of the lack of a proper democratic politics?

That is too quick. As I said, markets can exist in non-democratic contexts. But a lot of what looks like a market transaction is actually theft-as when dictators sell their country's resources on the world market and pocket the results of the sale. And in countries like Nigeria, you have weak enforcement of property rules, a weak banking system, and widespread corruption. These all undermine the ability of a market to work. But clearly markets can exist and still work to the benefit of dictators. And some markets help keep dictators in power-here I have in mind child labor and bonded labor markets which keep the population passive and uneducated.

Are state-imposed and enforced measures to ensure that workers voluntarily choose to enter into contracts genuine 'limits' to the market? Or are they rather measures to install a genuine ('ideal') market in the first place? So is debt peonage or child labor compatible with an ideal market, given the ideal market's prerequisite of the absence of asymmetric bargaining power? And more generally, what exactly is the concept of a 'limit' to the market that underlies your work?

I think true laissez faire is impossible. The existence of a market system depends on there being limits, on there being enforcement of property rules for example, i.e., on taking some options off the table. 
My first line of criticism is that in reality in a lot of these cases in the developing world we do not have actual markets, and so a lot of the problems we see are not so much problems with the market, but problems of the absence of an established market. But even if we created the conditions for a market in child labor-which could be done-there are still reasons for concern about that market.

My second line of criticism is that, even if these markets involved free exchange between equals, we would have reasons to object and that goes back to what I said earlier about not accepting the fact that an exchange is voluntary as sufficient for its legitimacy. Some things that are voluntarily exchanged are still wrong (see also, Satz 2007). Even if vote-trading is voluntary and involves trading between equals, we have reasons to object to it.

A lot of the markets that I look at are very non-ideal markets, and that is why my approach is not so hostile to economic reasoning. Standard economic reasoning can take a lot of my framework on board. It is already concerned with externalities and what I refer to as weak agency. At the same time, although I use the economic term "externality", I am quite specific about the kinds of externalities I think are troubling. I think it is a problem in economics that the notion of externality is ill-defined-it is an empty term that needs filling in, since, as I said, almost every exchange generates some kind of externality.

\section{Where do you think the debate about the limits of the market in political philosophy is heading?}

I think the debate has moved to particular issues such as markets in the media, or education or healthcare. I think there is a huge amount of work to be done by political philosophers thinking about alternative modes of distribution in those domains. How, for example, should we think about the distribution of media time; what should we do when the production of for profit print news no longer seems viable; how should health care be distributed. How should education be funded? The environment will be another place where debates about the market become salient. There have already been debates about carbon markets, but what about the cultural services that nature provides? How should a community's way of life as fisher-people be taken into account in our environmental decision making? I also think the recent economic shock is going to make people more skeptical about financial markets, markets in derivatives, and the like. So, I suspect there will be attention to that. 
More generally, I suspect that there will be an increased focus on institutional delivery systems-centralized versus non-centralized modes of provision; underlying property rules, especially about intellectual property; and forms of public service provision in poor countries.

\section{REFERENCES}

Arrow, Kenneth. 1972. Gifts and exchanges. Philosophy and Public Affairs, 1 (4): 343362.

Cohen, Gerald A. 1978. Karl Marx's theory of history: a defence. Princeton (NJ): Princeton University Press.

Frey, Bruno. 1997. Not just for the money: an economic theory of personal motivation. Boston (MA): Beacon Press.

Gneezy, Uri, and Aldo Rustichini. 2000. A fine is a price. Journal of Legal Studies, 29 (1): 1-18.

Hausman, Daniel M. 1995. Rational choice and social theory: a comment. Journal of Philosophy, 92 (2): 96-102.

Posner, Richard. 1992. Sex and reason. Cambridge (MA): Harvard University Press.

Satz, Debra. 1992. Markets in women's reproductive labor. Philosophy and Public Affairs, 21 (2): 107-131.

Satz, Debra. 1995. Markets in women's sexual labor. Ethics, 106 (1): 63-85.

Satz, Debra. 2004. Noxious markets: why should some things not be for sale? In Economic theory, philosophy and contemporary social issues, eds. Prasanta Pattanaik, and Stephen Cullenberg. New Delhi: Oxford University Press, 11-38.

Satz, Debra. 2007. Liberalism, economic freedom and the limits of markets. Social Philosophy and Policy, 24 (1): 120-140.

Satz, Debra. 2008. The moral limits of markets: the case of human kidneys. Proceedings of the Aristotelian Society, 108 (3): 269-288.

Satz, Debra, and John Ferejohn. 1994. Rational choice and social theory. Journal of Philosophy, 91 (2): 71-87.

Satz, Debra, and John Ferejohn. 1995. Unification, universalism and rational choice theory. Critical Review, 9 (1-2): 71-84.

Summers, Lawrence. 1991. Untitled Memo. Reprinted in Daniel M. Hausman, Michael S. McPherson. 2006. Economic analysis, moral philosophy, and public policy. New York: Cambridge University Press, 12-13.

Titmuss, Richard Morris. 1970. The gift relationship: from human blood to social policy. Sidney: Allen \& Unwin.

Debra Satz's Website:

$<$ http://philosophy.stanford.edu/profile/Debra+Satz/>

Bowen H. McCoy Family Center for Ethics in Society:

$<$ http://ethicsinsociety.stanford.edu/> 